\title{
A Critical Discourse Analysis of Gender Disparity in Taskmaster
}

\author{
Nauka Nayana Prasadini \\ Universitas Negeri Yogyakarta, Yogyakarta \\ naukanayana.2018@student.uny.ac.id
}

\begin{abstract}
British comedy panel show is the television comedy genre that is known for spontaneous banters and humor. Despite the popularity, the shows in this genre are often criticized as "male-dominated" and heavily gender-biased. As one of the most popular comedy panel shows, Taskmaster also shows the same problems, despite having more women in the future series. Therefore, the study analyses the gender disparity as showed in Taskmaster through the perspective of Critical Discourse Analysis (CDA). The study uses a qualitative approach, focusing on CDA. Moreover, the data was taken from the Series 2 of Taskmaster using open coding technique and analyzed with Fairclough's Critical Discourse Analysis framework. The results show that throughout the series, the only woman panelist is often being underestimated and interrupted by men, confirming gender disparity in Taskmaster. She is also constantly being objectified while defending her attempts, as this occurrence increases throughout the episodes. Interestingly, some of the men panelists and presenters try to diminish the male-dominated nature by helping in weighing sexistsounding tasks or decisions. This also confirmed existing opinions that men often hold more power in comedy panel shows than women.
\end{abstract}

Key words: Critical discourse analysis, Taskmaster, comedy panel show, gender disparity.

\section{INTRODUCTION}

British panel show is one of the kinds of television comedy genre that will never be the same outside of the United Kingdom. This genre is known for the panelists, often dominated by comedians, who throw banters on the selected topic of discussion. Panel show is also often synonymously compared to quiz show and game show due to its light-hearted atmosphere (Brock, 2021). Its distinctive way of serving humor through spontaneity and improvisation creates a different way of seeing comedy on television.

However, British comedy panel shows are often criticized as "maledominated" and heavily gender-biased. This is because male comedians often compete with each other, letting the female comedians do not have the same chance 
to participate in the panel show fully and, most of the time, not trying to win the conversation (Khan, 2009; Martin, 2008). The statements align with the theory of "allpurpose male oppressor," where men tend to interrupt and dominate conversations with women (Frazer et al., 1997). The critiques on the male-dominated nature in British comedy panel shows have been addressed toward several panel shows, including Mock the Week, Big Fat Quiz of the Year, and 8 Out of 10 Cats (Khan, 2009; Lawson \& Lutzky, 2016; Martin, 2008; Weber, 2017). Although there are many maledominated comedy panel shows, some of the shows have done some steps in reducing this problem. One of the shows on this list is Taskmaster.

Taskmaster (2015-present), devised by Alex Horne, is a British comedy panel show that combines comedians' attempts in doing eccentric tasks and their arguments in defending their attempts. In recent years, the show has shown more diversity, including adding more women and People of Color (POC) among the panelists. As the show creator, Horne also stated that this attempt would readdress the gender and cultural background imbalance on the show (Bernhardt, 2021). Despite their progressive step, Taskmaster was the same as other panel shows in its early years: it was heavily dominated by men. In Series 1 until 3, the show only has one woman in each panel of the series. Since there is only one woman in each panel, the show often unconsciously did unfair biases toward women, whether in the tasks or during the studio conversation.

Considering the imbalance that previously happened in the early series of Taskmaster, it is necessary to delve more into the nature of gender disparity in panel shows. One of the ways to examine the issue is through Fairclough's concept of Critical Discourse Analysis (CDA). Fairclough (2010) stated that discourse can be analyzed through transdisciplinary analysis, using a comprehensive examination of a text and addressing the existing social problems discursively. The nature of this approach makes it possible to analyze the existing social issues in British panel shows, specifically gender disparity and male domination (Lawson \& Lutzky, 2016). Although British panel shows is a fascinating topic to be analyzed considering the uniqueness 
among other comedy TV show genres, the subject is still lacking existing research in the critical discourse analysis' area.

This paper would like to analyze the gender-based problems as shown in Taskmaster through Fairclough's CDA principles. The CDA will be used to look closely at the panelists' and presenters' behaviors and statements related to gender disparity. Using CDA in this study will also reveal how gender disparity problems, mainly women's inferiority, sexism, and gender bias, impact the nature of the show.

\subsection{Critical Discourse Analysis}

Critical Discourse Analysis (CDA) is an approach that sees language as a form of social practice and a form of discourse that focuses on relational, dialectical, and transdisciplinary aspects (Fairclough, 2010; Janks, 1997). In the CDA context, the special practice is seen as a layered process between communications and abstract concepts, including languages, discourses, and genres. Fairclough (2010) stated several aspects of CDA. First, it contains a transdisciplinary analysis that relates discourse with other elements in the social process. Second, it includes a comprehensive systematic analysis of texts, whether it is in written, oral, or visual form. Finally, it addresses the social problems in discursive aspects and suggests options in handling the problem.

Janks (1997) interprets Fairclough's dimension in handling the CDA model: it has the object of analysis, it has a process in which the object is produced or received, and it also has a socio-cultural history, which becomes the background of the discourse. To conduct CDA, the analyzed object should pass three steps of analysis, which consist of text analysis (description), processing analysis (interpretation), and social analysis (explanation regarding social theory). This approach will enable researchers to focus on important discursive aspects, including specific linguistic selections, juxtaposition, and the historical determination of the selected object. 


\subsection{Gender Disparity in Comedy Panel Show}

There are not many studies discussing gender disparity in comedy panel shows, but two studies stand out in discussing how gender plays a major role in the television genre (Lawson \& Lutzky, 2016; Weber, 2017). Lawson and Lutzky (2016) discuss how gender plays a role in another comedy panel show, Mock the Week. They found that females contribute less than male panelists through a sociolinguistic perspective, as males tend to interrupt most frequently. Their findings support previous news coverage on the issue, in which men often dominated panel shows, resulting in women being cut out in the panel shows' editing room (Khan, 2009; Moody, 2019; The Week, 2018).

Weber (2017) took a different turn in discussing the gender disparity issue. In Weber's study, the focus is stirred into how gender imbalance in comedy panel shows stems from the masculinity domination in British comedy and culture. Through the discourse analysis perspective in opinions expressed about panel shows, it is found that most British producers and media personalities ignore the male dominance in panel shows. To support the statement, Weber also analyses the interactions in 8 Out of 10 Cats, which proves that comedy panel show often favors "heterosexual masculine identities," creating a larger masculine space in comedy panel show (Weber, 2017, p. ii).

\subsection{Taskmaster}

As previously mentioned in the Introduction, Taskmaster is a British comedy panel show that combines five comedians' attempts in a series of fiendish yet creative "tasks" and their studio banters. In the studio recording, the selected comedians defend their attempts in front of the Taskmaster himself, Greg Davies, and Alex Horne as the "Taskmaster's Assistant."

From the gender perspective, the show has always has women in the panel since it premiered on 28 July 2015 . However, there is a gap between the numbers of men and women on the show. This can be seen from one female contestant in each panel throughout Series 1-3 (Roisin Conaty in Series 1, Katherine Ryan in Series 2, and 
Sara Pascoe in Series 3). Further evidence on the gender disparity in the number of contestants was also provided by Ash and Lowe (2020), in which there is $38.8 \%$ of women's appearance on the show, compared to $69.2 \%$ of men's appearance, ignoring the regular presenters. Although the data is outdated since it only calculates women's appearances throughout Series 1-7, the data still shows the actual gender disparity until the latest series in 2021. Among 60 contestants that appeared on the show, only $38.3 \%$ or 23 women contestants have participated. This is a low number compared to the 37 men who have appeared on the show. As previously mentioned in the Introduction, the gender disparity in the numbers of women panelists is readdressed in the further series of Taskmaster.

Although there is a gap in the number of women contestants, the women contestants still shine across the show. In total, five women won the overall series. Their victories in the respective series show that despite competing with men and defending their attempts in front of both male presenters, they can still prove their competence and comedic skills, regardless of their gender.

\section{METHODS}

The problems will be analyzed in a qualitative approach study, in which the result and the analysis will be presented in the form of reasoning and description (Given, 2008). Critical discourse analysis (CDA) will also be used in this study to analyze the result, following the steps of analysis as proposed by Fairclough (2010) and Janks (1997).

The data for this study is taken from 5 episodes in Series 2 of Taskmaster. All episodes are lasted for around 40-45 minutes. There are several reasons behind the decision to choose this series. To begin with, the series is the second series that only has one woman in the entire panel. The series also has fewer episodes than other series (5 episodes), making the data easier to analyze for the study's purposes. Moreover, another significant reason for this decision is because Katherine Ryan, the only woman contestant in this series, was the first woman to win Taskmaster. Her victory in this series eventually paved the way for other women contestants to win 
their respective series, proving that this series has a significant role for women contestants in Taskmaster.

The data will be gathered using the open coding technique. Open coding is a data-gathering technique that classifies ideas for further interpretation (Given, 2008). This technique is important concerning CDA since it will help in locating underlying themes on the subjects. This technique is also used to measure the number of occurrences, mainly in interpersonal communication. Several themes to be looked at are stated as the following:

1. The number of times and the content of females lead the conversation.

2. The number of times female being interrupted by the male.

3. The number of times and the content of females being objectified, ignored or underestimated by the male.

4. The duration of interpersonal communication is based on the previous criteria.

\section{RESULTS \& DISCUSSION}

Before analyzing the show with CDA, all episodes in Series 2 of Taskmaster are measured based on the open coding technique and criteria in the Methods. After analyzing 225 minutes of materials, the result is shown in the following table.

Table I. Six measures to determine gender disparity

\begin{tabular}{|c|c|c|c|c|c|c|c|}
\hline & \multicolumn{6}{|c|}{ Women's inferiority and gender bias } & \multirow{2}{*}{$\begin{array}{c}\text { Sexism } \\
\text { Women being } \\
\text { sexualized/ } \\
\text { objectified by } \\
\text { men }\end{array}$} \\
\hline $\begin{array}{c}\text { Taskmaster: } \\
\text { Series } 2\end{array}$ & $\begin{array}{l}\text { Men leading } \\
\text { conversation }\end{array}$ & $\begin{array}{c}\text { Women } \\
\text { leading } \\
\text { conversation }\end{array}$ & $\begin{array}{c}\text { Men } \\
\text { underestimate } \\
\text { women's } \\
\text { opinion }\end{array}$ & $\begin{array}{c}\text { Women } \\
\text { interrupting } \\
\text { men }\end{array}$ & $\begin{array}{c}\text { Men } \\
\text { interrupting } \\
\text { women }\end{array}$ & $\begin{array}{l}\text { Women } \\
\text { being } \\
\text { ignored } \\
\text { by men }\end{array}$ & \\
\hline $\begin{array}{l}\text { "Fear of } \\
\text { Failure" } \\
\text { Ep. } 1\end{array}$ & 8 & 3 & 2 & 1 & 2 & 3 & 0 \\
\hline $\begin{array}{l}\text { "Pork Is a } \\
\text { Sausage" } \\
\text { Ep. } 2\end{array}$ & 10 & 3 & 2 & 0 & 1 & 0 & 1 \\
\hline $\begin{array}{l}\text { "A Pistachio } \\
\text { Éclair" Ep. } 3\end{array}$ & 12 & 3 & 2 & 0 & 2 & 0 & 1 \\
\hline $\begin{array}{l}\text { "Welcome } \\
\text { to Rico } \\
\text { Face" Ep. } 4\end{array}$ & 10 & 2 & 6 & 0 & 2 & 0 & 3 \\
\hline
\end{tabular}




\begin{tabular}{|l|c|c|c|c|c|c|c|}
\hline $\begin{array}{l}\text { "There's } \\
\text { Strength in } \\
\text { Arches" } \\
\text { Ep.5 }\end{array}$ & 10 & 4 & 6 & 2 & 4 & 1 & 3 \\
\hline TOTAL & 50 & 15 & 8 & 3 & 9 & 4 & 9 \\
\hline
\end{tabular}

The result shows that among 98 occurrences measured, it is found that 33 occurrences display gender disparity in Series 2 of Taskmaster. The spread of occurrences including "men leading conversation" (51\%) "women's opinion are underestimated by men" (8.1\%), "women interrupting men" (3\%), "men interrupting women" (9.1\%), "women being ignored by men" (4\%), and "women being sexualized or objectified by men" (9.1\%). Despite many forms of gender disparity, the only women in the panelists of Series 2, Katherine Ryan, still have 14 chances (15.3\%) in leading the conversation.

As the number shows, one of the highest gender disparity occurrences in the Series 2 of Taskmaster is how men led most of the conversation of the show. The result is not surprising considering that both main hosts of the show are men, and it is quite normal to have male hosts in British panel shows. However, the comparison between men and women is highly unbalanced, especially considering that Series 2 only have one woman as the panelist. This leads to men having more competitive and wanting to dominate each other in existing conversation, leading women not given chance to lead the conversation as well (Lawson \& Lutzky, 2016). The imbalance eventually creates more disparity, as women are not having the same chance to participate in most comedic banters that were happening on the show.

The second-highest gender disparity occurrence is women being underestimated based on her statements by the men. This category is tied within whether women were interrupted by men or not. The problem is illustrated by one of the conversations between Katherine Ryan, as the only woman panelist, Greg Davies as the presenter, and Jon Richardson and Richard Osman as two of four men panelists. In the context of the conversation, the four of them discussed their attempts to make a stop-motion film with a potato. In the conversation below, they 
discussed Katherine's attempt to represent women through "female potato James Bond."

Jon: I did wonder about the narrative of the potato who for no reason gets trod on by a high heel. What was that about?

Greg: James Bond films are often characterized by a preposterous ending. Richard: Yeah, but that just didn't make any sense. There was no narrative arc whatsoever.

Katherine: [cutting in] A feminist arc. I will be the first female potato James Bond.

Richard: The feminist "ark" is, of course, what Noah's wife... [audience erupted laugh] That's what she built.

Katherine: [on serious tone] Bond should die with all the sexual harassment he does.

Richard: I don't disagree with that. But it's just not in the... Not in the spirit of the film.

"The Strengths in the Arches" in Taskmaster (Horne \& Devonshire, 2016).

With her short film, Katherine suggested her feminist view on female "James Bond," considering how she emphasized the phrase "feminist arc" in her statement. However, Richard joked about her "feminist arc" view, condescending her view, and compared it to Noah's wife in the Bible. Katherine was not pleased with his reply, as Katherine replied, "Bond should die" without even laughing. The whole conversation suggested that Katherine wanted her voice to be heard, as she was the only woman in the panel. This pushed her to deliver her feminist view while defending her task attempts. Regardless, the men panelists ridiculed her statements as they were biased by her gender.

The same occasion also happened in the same episode when Katherine mentioned that she had education in urban city planning but could not create a bridge only with rubber in one task. During this scene, the men were seemingly disappointed in her, and one of them, Doc Brown, said, "You know where you lost 
that task, Katherine? You lost it in that moment where you said, "People aren't ready for how smart I am." While the statement was considered harmless in this context, Doc actually mocked Katherine's intelligence with her educational background. The statement implied that Katherine, despite being an educated woman, cannot do simple things, unlike men. Interestingly, when other men panelists (Doc Brown and Jon Richardson) did the same task with Katherine, no one questioned or debated their attempts.

Taskmaster also displayed several occurrences of women being sexualized or objectified (27.2\%), whether by the men panelists or the presenters. The occurrences mainly exist in the comments from the men when Katherine expresses her opinions regarding her tasks' attempts. An illustration of this issue can be seen in the fourth episode, in which the panelists must conceal a pineapple in their bodies. Katherine later commented about her attempt:

Katherine: [about the task] I don't even think I could do a courgette. I want to clear that up.

Joe: I'll be honest with you, there is a page on that in my book. [audience laughed]

"Welcome to Rico Face" in Taskmaster (Horne \& Devonshire, 2016)

As preserving context, previously, Joe Wilkinson, another panelist, brought a pornographic book as his prize task. Later on, in the episode, Katherine said that she could not "do a courgette," meaning that she cannot conceal a courgette. As a response, Joe replied, "I'll be honest with you, there is a page on that in my book.", giving a sign that Katherine might do something sexual with the courgette and it possibly exists in the pornographic book. This erupted laughter from the audience, suggesting that most audiences accepted the sexist joke from Joe. Katherine, however, tried to ignore Joe's sexist comment by trying to laugh along with it. Katherine's ignoration was not a sign of her defeat toward the sexism, but to show her resistance toward the problem. 
What made it even more interesting is that Katherine's strategy in challenging the gender disparity on the show is not only by getting along with the gender-biased comments or jokes but also by questioning sexist statements or decisions. An illustration best to describe her defense toward the disparity was shown when Katherine and other men panelists receive a final task, in which they must: "Put on a pair of food-handling gloves. Eat a whole banana. Correctly put on a tie and clap as many times as possible. All tasks must be completed within 100 seconds." As much as the task sounds ridiculous and in line with Taskmaster's comedic choice, Katherine questioned the statement in which all contestants must "correctly put on a tie." The following is the complete transcript.

Greg: I sense an objection coming from Katherine.

Katherine: What the fuck?

Alex: Thank you. Great reading.

Katherine: [running around Alex] No, I didn't listen to the last bit because this is an example of the type of top-down misogyny that keeps people like me losing!

Alex: I don't know how to react to that.

Katherine: Shut up!

Greg: You don't know how to put a tie on? Is that it?

Katherine: No! Let's all put on a tampon, and then we'll see... [audience applause and cheering]

Jon: I'll put your tie on if you'll eat my banana! [audience laugh] I'm married now, so that's where it ends.

"The Strengths in the Arches" in Taskmaster (Horne \& Devonshire, 2016)

Through the conversation, it is apparent that Katherine rejected the "misogynistic" task of asking the panelists to wear a tie properly. Tie is often identified with traditional masculine gender norms, and it is implied that Katherine was not the kind of person exposed to the clothing norm and is unable to wear a tie. Instead of keeping silent, she blatantly expressed her disapproval of the task, only to be attacked by Jon Richardson. In his last comment, he implied wanting to do her task 
in exchange for sexual activity through "eating my banana," as it described his male reproduction organ. Most of the audience accepted this joke as the crowd erupted with laughter. However, this is a harmful occasion since this kind of joke creates an opportunity for men to vocalize misogynistic views to deny something criticizable (Bilig in Weber, 2017).

This interaction was intriguing because some of the men realized how harmful the sexist-sounding task and comments would be. This is shown in the continuation of the previous conversation:

Greg: Katherine might have a point. I'm just thinking if there's something...

Richard: [cutting in] Tell you what. I'm gonna read all the words here. I'm gonna move one comma and we'll see if we can sort this out. Put on a pair of food-handling gloves, eat a whole banana correctly. Put on a tie and clap as many times as possible.

Greg: Done! Surely!

Katherine: I just feel now that I've ruined the task.

Greg: Oh, no, no. Not at all(!)

Jon: Now we see the trouble that coin has got us into, don't we?

The Strengths in the Arches" in Taskmaster (Horne \& Devonshire, 2016)

Through this conversation, Greg Davies, as the main figure of authority in this show, implicitly agreed with Katherine's view. He defended her arguments and made another panelist, Richard Osman, change the task. The task later turned into "eat a whole banana correctly," not "correctly put on a tie," which made everyone, regardless of their gender, able to complete the task.

Katherine's arguments and constructive suggestions from panelists and presenters eventually turn the task into a more gender-balanced way. Their conversations across the second series of Taskmaster eventually proved that the gender disparity problem could be slowly resolved through women's strategies in expressing arguments and holding onto their position in the show. However, the strategies and arguments expressed by women would not work alone without both 
men and women agreeing to shift away from masculine-centered humor and the perpetuated gender disparity in it (Weber, 2017).

\section{CONCLUSIONS}

Regardless of being a show that already displays women in their panelists since the beginning, Taskmaster still cannot resist the existing male-dominated nature in the British comedy panel show. The result describes the number of disparity occurrences on the show. Then, each of the disparity elements is analyzed with Fairclough's Critical Discourse Analysis principles, which includes transdisciplinary analysis, comprehensive systematic analysis of the text, and addressing the social problems. As the discussion suggests, the gender disparity issues have been rooted in the imbalance of the existing panelists in the Series 2 of Taskmaster. The imbalance eventually made the men panelists treat the women differently, as they showed sexism and gender-biased views to the only female panelist in Series 2, Katherine Ryan. Despite the dispersed treatments that were often let out by the men, some of the panelists sometimes realize how important Katherine's view regarding the gender balance on the show.

Moreover, the discussion also suggests that gender disparity is not a problem that cannot be solved only by placing token women among the panelists. However, it can be solved if women have strategies in shifting the gender-based conversation. One strategy is to shift masculine-centered humor and the gender disparity that perpetuates the imbalance on the show. As in the case of the Series 2 of Taskmaster, Katherine Ryan has done these strategies, and even stands up to fight the gender disparity in the show. The show eventually grows into a more diverse comedy panel show in the future years, thanks to her stance.

\section{REFERENCES}

Ash, R., \& Lowe, S. (2020). UK Panel Show Gender Breakdown. https://strudel.org.uk/panelshows/shows/taskmaster.html

Bernhardt, J. (2021). "Reinvent the macarena": Taskmaster's Alex Horne sets us four 
fiendish new challenges. The Guardian. https://www.theguardian.com/tv-andradio/2021/mar/18/taskmaster-alex-horne-new-challenges-interview

Brock, A. (2021). Hybrid TV Comedy Genres - The Case of Comedy Panel Shows. Estudios de Lingüística Del Español, 43, 9-22. https://infoling.org/elies/43/elies43-1.pdf

Faiclough, N. (2010). Critical Discourse Analysis (Second). Routledge.

Fairclough, N. (2010). Critical Discourse Analysis: The Critical Study of Language. 9781405858229.

Frazer, T. C., Johnson, S., \& Meinhof, U. (1997). Language and Masculinity. Blackwell Publishers. https://doi.org/10.2307/417526

Given, L. M. (Ed.). (2008). The SAGE Encyclopedia of Qualitative Research Method. https://books.google.com/books?id=y_OnAQAAMAAJ\&pgis=1

Horne, A., \& Devonshire, A. (2016). Taskmaster. Avalon Television.

Janks, H. (1997). Critical Discourse Analysis as a Research Tool. Discourse: Studies in the Cultural Politics of Education, 18(3), 329-342. https://doi.org/10.1080/0159630970180302

Khan, U. (2009). TV panel shows are too "male dominated", claims Victoria Wood. The Telegraph, June.

Lawson, R., \& Lutzky, U. (2016). Not getting a word in edgeways? Language, gender, and identity in a British comedy panel show. Discourse, Context and Media, 13, 143-153. https://doi.org/10.1016/j.dcm.2016.04.002

Martin, N. (2008, November). Comedy panel shows are "testosterone fuelled", says BBC Radio 4 presenter. The Telegraph.

Moody, H. (2019). Why Do Panel Shows Insist on Having A Token Woman? https://funnywomen.com/2019/01/25/why-do-panel-shows-insist-on-havinga-token-woman/

The Week. (2018). Sandi Toksvig: women are being 'edited out and marginalised' of panel shows. https://www.theweek.co.uk/96406/sandi-toksvig-women-arebeing-edited-out-and-marginalised-of-panel-shows?amp

Weber, L. A. (2017). "Don't Be Such a Girl, I'm Only Joking!": Post-alternative Comedy, British Panel Shows, and Masculine Spaces (Issue August). University of Wisconsin-Milwaukee. 